\title{
Goniometric Estimation of Treatment Efficiency in Pediatric Midshaft Forearm Fracture Patients
}

\author{
Upenieks Janis*,**, Sloka Sintija***, Petersons Aigars*,**, Villerusa Anita**** \\ * Department of Pediatric Surgery, University Children's Hospital (Riga, Latvia), \\ **Department of Pediatric Surgery, Riga Stradins University (Latvia), \\ ***The Centre for Disease Prevention and Control of Latvia \\ **** Department of Public Health and Epidemiology, Riga Stradins University (Latvia)
}

\begin{abstract}
Summary.
Introduction. The overall forearm fracture rate is extremely high in pediatric population, significantly being composed of forearm midshaft fractures. Conservative vs. operative treatment are the two competing approaches being introduced for treatment of these fractures depending on the type and localization of the fracture as well as on the age of children. Objective measurements of ROM and correct interpretation of the results can have a substantial impact on the development of the scientific basis of therapeutic interventions.

Aim of the study. 1) to evaluate ROM in elbow and wrist joints using goniometry, comparing conservatively and operatively treated forearm fracture patients with healthy controls; 2) to estimate limitation of ROM that causes subjective complaints; 3 ) to determine if potential limitations of ROM can be the main argument for choice of treatment method despite the age and gender of the child.

Materials and methods. Stratified randomized controlled prospective clinical trial from 2010 to 2012 was performed including comparable groups of conservatively and operatively treated boys and girls (age 7-15 years), 6 months after forearm midshaft fracture, compared to similar groups of children without fractures. Total number of respondents was 180 children (30 in each group). Length of immobilization for all treated children was 4 weeks ( $28 \pm 2$ days). None of the included patients was administered to special rehabilitation course. During follow-up active ROM of elbow (flexion, extension, pronation, supination) and wrist (flexion, extension, abduction and adduction) joint was assessed using standard plastic goniometer. All measurements were performed by one person, the same tool, twice for each patient. All children together with parents filled questionnaires about self-estimation of functional status (PedsQL v3.0) before (all groups) and after trauma (treated patients only). Each parent signed informed consent of the participation in the research, hospital's ethical committee gave the approval for the study.

Results. All fractures consolidated. Statistically significant differences were detected comparing both non-operated and operated patients to controls. Both - conservative and operative treatment predicted higher level of ROM limitation rate, compared to controls. Conservative treatment predisposes patients to significantly higher ROM limitation - $75.0 \%$, compared to operated patients $31.7 \%$. Most of limitations in all four treated groups were asymptomatic: $77.8 \%$ in conservative groups; $63.2 \%$ in operated groups; and $100 \%$ in controls groups. Subjective complaints of ROM limitations in conservatively treated children were about elbow flexion, elbow pronation and supination and wrist extension. Operated children complained of limited elbow flexion, elbow supination and wrist extension. There were no gender differences amon g conservatively and operatively treated groups, both girls and boys had $53.3 \%$ limitation rate. Dominant hand was injured more often (ratio $=1.14: 1)$. No statistically significant differences were found in all three age groups (7-9 years, 10-12 years and 13-15 years) in both genders, comparing to other age groups of the same gender. Conclusions. The results of this study indicate superior effectiveness of elastic stable intramedullary nailing over conservative approach. Frequency of ROM limitations performing surgical stabilization is more than twice lower than that of conservatively treated children. Only moderate $\left(>20^{\circ}\right)$ limitations of ROM cause subjective complaints. Although compensatory capacities of a growing child are high and therefore most limitations of ROM are asymptomatic and do not reduce quality of life, it advocates surgical treatment to become the golden standard for midshaft forearm fracture treatment in pediatric population. The age and gender of a child does not influence frequency and severity of ROM limitations therefore should not be considered as the main arguments while choosing treatment method.
\end{abstract}

Keywords: Forearm fractures, children, treatment options, goniometry.

\section{INTRODUCTION}

The total fracture rate in pediatric population significantly is being composed of these affecting forearm bone fractures, especially in 7-15 years old children; some authors mention even $40-50 \%(22,26)$. Pediatric diaphyseal forearm fractures are ranked in 3 rd position after distal forearm and supracondylar fractures (8). Conservative vs. operative treatment are the two competing approaches being introduced for treatment of these fractures depending on the type and localization of the fracture as well as on the age of children. Objective evaluation of functional outcome is performed rarely, especially when children show no complaints of functional limitations. Therefore it is hard to compare functional outcomes from objective (doctor's view) and subjective (patient's view) perspectives after application of different treatment methods. Objective measurements of ROM and correct 
interpretation of the results can have a substantial impact on the development of the scientific basis of therapeutic interventions.

\section{AIM OF THE STUDY}

The aim of our study is 1) to evaluate ROM in elbow and wrist joints using goniometry, comparing conservatively and operatively treated forearm fracture patients with healthy controls; 2) to estimate limitation of ROM that causes subjective complaints; 3) to determine if potential limitations of ROM can be the main argument for choice of treatment method despite the age and gender of the child.

\section{MATERIALS AND METHODS}

The design of study was stratified randomized controlled prospective clinical trial from 2010 to 2012. Six groups of 7-15 years old patients were included ( 30 children each: $7-9$ years $(n=10), 10-12$ years $(n=10)$ and 13-15 years $(n=10))$. Group I and II were girls and boys, respectively, $6 \pm 1$ months after both bone forearm midshaft fractures, treated conservatively by closed reduction and plaster immobilization. Group III and IV were girls and boys, respectively, with the same trauma localization and duration, but treated surgically by intramedullary nailing (ESIN) followed by plaster. Group V and VI were girls and boys, respectively, without forearm fractures, admitted to the hospital due to other conditions.

Conservative group patients were admitted to hospital, closed reduction under general anesthesia using fluoroscopy control was performed, followed by over-the-elbow immobilization in plaster of Paris. Operative treatment group patients were admitted to hospital, operation was performed under general anesthesia, using fluoroscopy control. After closed reduction of fracture two $2.0,2.5$ or $3.0 \mathrm{~mm}$ elastic Nancy nails were introduced: retrograde in radius (perforation level - distal metaphysis, anteromedial surface) and antegrade in ulna (perforation level olecranon ulnae, posterolateral surface). Nail diameter (d) was chosen according to medullary canal diameter at fracture site (D), using formula:

$\mathrm{d}=0.4 \mathrm{D} ;(1)$

Nail length (l) was chosen according to bone length (L), in order not to cross growth plates, using formula: $\mathrm{l}=\mathrm{L}-4(2)$

Nails were buried under the skin; over-the-elbow plaster of Paris was applied.

Both conservative and operated patients were discharged next day after X-ray control for further follow-up on out-patient basis. Length of immobilization for all treated children was 4 weeks (28 \pm 2 days), then plaster was removed, control X-rays were performed and patients were allowed to use their arms in everyday activities. None of the included patients was administered to special rehabilitation course. Control group patients underwent investigation and questionnaire during their stay at hospital due to other conditions. During follow-up active ROM of elbow (flexion, extension, pronation, supination) and wrist (flexion, extension, abduction and adduction) joint was assessed using standard plastic goniometer. All measurements were performed by one person, the same tool, twice for each patient, to avoid intertester, intertool and intratester errors.

Limitations of ROM less than $10^{\circ}$ were considered to be either measurement errors or interside differences. Limitations $10-19^{\circ}$ were considered to be mild, 20-29 - moderate and $>30^{\circ}$ - severe. Patients, who met the criteria for exclusion, were replaced by appropriate respondents. Exclusion criteria were: 1) patients who refused or failed to attend follow-up session due to compliance problems; 2) patients with single bone surgical stabilization using one elastic nail; 3) patients with "complicated" fractures in terms of refracture, open fracture, secondary dislocation and wound infection; 4) patients who had their nails removed prior to follow-up term.

All children together with parents filled questionnaires about self-estimation of functional status (PedsQL v3.0) before (all groups) and after trauma (groups I-IV). Each parent signed informed consent of the participation in the research, hospital's ethical committee gave the approval for the study.

Raw data was processed using the software package SPSS v20.0. In data analysis descriptive statistical methods were used. To determine the statistical reliability $\chi^{2}$ test was employed. The statistical significance for all tests was set at $\mathrm{p}<.05$. Characteristics of data used crosstabs and $95 \%$ confidence interval set for comparison.

\section{RESULTS}

All fractures consolidated, no healing disturbances in terms of malunion or nonunion were documented. 19 respondents of treated patients were withdrawn, as they met exclusion criteria mentioned above, and substituted by respondents of the same age group (see Table 1). 
Table 1. Overview of excluded and substituted respondents

\begin{tabular}{|c|c|c|c|}
\hline Group & $\begin{array}{l}\text { Age of } \\
\text { respon- } \\
\text { dent }\end{array}$ & Cause & $\begin{array}{l}\text { Age of } \\
\text { substi- } \\
\text { tute }\end{array}$ \\
\hline \multirow[t]{4}{*}{ I } & 7 & Malalignment & 8 \\
\hline & 10 & Malalignment & 10 \\
\hline & 11 & Malalignment & 12 \\
\hline & 12 & Refused follow-up & 12 \\
\hline \multirow[t]{6}{*}{ II } & 8 & Malalignment & 7 \\
\hline & 12 & Malalignment & 11 \\
\hline & 8 & Malalignment & 8 \\
\hline & 9 & Malalignment & 8 \\
\hline & 15 & Refused follow-up & 14 \\
\hline & 13 & Failed to follow-up & 13 \\
\hline \multirow[t]{4}{*}{ III } & 12 & Refused follow-up & 11 \\
\hline & 14 & Refused follow-up & 13 \\
\hline & 8 & Refused follow-up & 8 \\
\hline & 10 & Removed prior follow-up & 10 \\
\hline \multirow[t]{5}{*}{ IV } & 15 & Refused follow-up & 14 \\
\hline & 9 & Failed to follow-up & 8 \\
\hline & 14 & Failed to follow-up & 15 \\
\hline & 11 & Wound infection & 10 \\
\hline & 11 & Removed prior follow-up & 12 \\
\hline
\end{tabular}

Statistically significant differences were detected comparing both non-operated Groups I and II) and operated (Groups III and IV) patients to controls (Groups V and VI): $\mathrm{p}<.001 \quad\left(\chi^{2}=64.669 ; \mathrm{df}=1\right)$ and $\mathrm{p}<.001\left(\chi^{2}=16.681 ; \mathrm{df}=1\right)$, respectively.

Both - conservative and operative treatment predicted higher level of ROM limitation rate, compared to controls $\mathrm{p}<.001\left(\chi^{2}=43.062 ; \mathrm{df}=1\right)$, i.e. $53.3 \%$ of cases ( $\mathrm{n}=64 ; 95 \%$ CI $44.4-62.0 \%$ ) manifest limitations, while control groups had only $3.3 \% \quad(n=2 ; 95 \%$ CI .9-11.4\%).

Conservative treatment predisposes patients to significantly higher ROM limitation - $75.0 \% \quad(n=45$; 95\% CI 62.8-84.2\%) compared to operated patients $31.7 \%(\mathrm{n}=19 ; 95 \%$ CI $21.3-44.2 \%), \mathrm{p}<.001 ; \chi^{2}=20.886$; $\mathrm{df}=1$.

Most of limitations in all four treated groups were asymptomatic: $77.8 \%$ (35 of 45 ) in Group I and II; $63.2 \%$ (12 of 19) in Group III and IV, and $100 \%$ (2 of 2 ) in controls Group V and VI. Subjective complaints of ROM limitations in Group I were seen mainly due to elbow flexion ( 3 of 6 ), elbow pronation ( 1 of 1 ) and wrist extension ( 1 of 6 ). Group II showed symptoms of limited elbow flexion ( 1 of 5), elbow supination (2 of 3) and wrist extension ( 2 of 7). Group III manifested elbow flexion ( 2 of 4 ) and wrist extension ( 2 of 4 ). Symptomatic patients in Group IV complained of limited elbow flexion ( 1 of 3 ), elbow supination ( 1 of 1) and wrist extension (1 of 3). Group V and VI had one case of limited elbow flexion and wrist flexion, respectively, both patients were asymptomatic. Overview of all patient groups, included in this research is depicted in table 2 .

Table 2. Distribution of limitations in ROM and subjective complaints.

\begin{tabular}{|c|c|c|c|c|c|c|c|c|c|c|c|}
\hline & Joint & Elbow & Wrist & Total & & & & & & & \\
\hline & $\begin{array}{l}\text { Limi- } \\
\text { tation }\end{array}$ & Flexion & Extension & $\begin{array}{l}\text { Prona- } \\
\text { tion }\end{array}$ & $\begin{array}{l}\text { Supi- } \\
\text { nation }\end{array}$ & Flexion & \begin{tabular}{|l|}
$\begin{array}{l}\text { Exten- } \\
\text { sion }\end{array}$ \\
\end{tabular} & \begin{tabular}{|l|} 
Abdu- \\
ction
\end{tabular} & \begin{tabular}{|l|} 
Addu- \\
ction
\end{tabular} & $\begin{array}{l}\text { (\% of } \\
\text { group) }\end{array}$ & $\begin{array}{l}\% \\
\text { of all })\end{array}$ \\
\hline & Plane & Sagittal & Transverse & Sagittal & Frontal & & & & & & \\
\hline & Axis & Frontal & Vertical & Frontal & Sagittal & & & & & & \\
\hline \multirow[t]{3}{*}{ Group I } & W/o & $3(10.0)$ & $3(10.0)$ & $0(0)$ & $2(6.6)$ & $2(6.6)$ & $5(16.6)$ & $1(3.3)$ & $1(3.3)$ & $17(56.6)$ & $17(9.4)$ \\
\hline & $\mathbf{W}$ & $3(10.0)$ & $0(0)$ & $1(3.3)$ & $0(0)$ & $0(0)$ & $1(3.3)$ & $0(0)$ & $0(0)$ & $5(16.6)$ & $5(2.8)$ \\
\hline & $\mathbf{T}$ & $6(20.0)$ & $3(10.0)$ & $1(3.3)$ & $2(6.6)$ & $2(6.6)$ & $6(20.0)$ & $1(3.3)$ & $1(3.3)$ & $22(73.3)$ & $22(12.2)$ \\
\hline \multirow[t]{3}{*}{ Group II } & W/o & $4(13.3)$ & $3(10.0)$ & $2(6.6)$ & $1(3.3)$ & $2(6.6)$ & $5(16.6)$ & $1(3.3)$ & $0(0)$ & $18(60.0)$ & $18(10.0)$ \\
\hline & $\mathbf{W}$ & $1(3.3)$ & $0(0)$ & $0(0)$ & $2(6.6)$ & $0(0)$ & $2(6.6)$ & $0(0)$ & $0(0)$ & $5(16.6)$ & $5(2.8)$ \\
\hline & $\mathbf{T}$ & $5(16.6)$ & $3(10.0)$ & $2(6.6)$ & $3(10.0)$ & $2(6.6)$ & $7(23.3)$ & $1(3.3)$ & $0(0)$ & $23(76.6)$ & $23(12.8)$ \\
\hline \multirow[t]{3}{*}{ Group III } & W/o & $2(6.6)$ & $1(3.3)$ & $0(0)$ & $0(0)$ & $1(3.3)$ & $2(6.6)$ & $0(0)$ & $0(0)$ & $6(20.0)$ & $6(3.3)$ \\
\hline & $\mathbf{W}$ & $2(6.6)$ & $0(0)$ & $0(0)$ & $0(0)$ & $0(0)$ & $2(6.6)$ & $0(0)$ & $0(0)$ & $4(13.3)$ & $4(2.2)$ \\
\hline & $\mathbf{T}$ & $4(13.3)$ & $1(3.3)$ & $0(0)$ & $0(0)$ & $1(3.3)$ & $4(13.3)$ & $0(0)$ & $0(0)$ & $10(33.3)$ & $10(5.5)$ \\
\hline \multirow[t]{3}{*}{ Group IV } & W/o & $2(6.6)$ & $1(3.3)$ & $0(0)$ & $0(0)$ & $1(3.3)$ & $2(6.6)$ & $0(0)$ & $0(0)$ & $6(20.0)$ & $6(3.3)$ \\
\hline & $\mathbf{W}$ & $1(3.3)$ & $0(0)$ & $0(0)$ & $1(3.3)$ & $0(0)$ & $1(3.3)$ & $0(0)$ & $0(0)$ & $3(10.0)$ & $3(1.7)$ \\
\hline & $T$ & $3(10.0)$ & $1(3.3)$ & $0(0)$ & $1(3.3)$ & $1(3.3)$ & $3(10.0)$ & $0(0)$ & $0(0)$ & $9(30.0)$ & $9(5.0)$ \\
\hline \multirow[t]{3}{*}{ Group V } & W/o & $1(3.3)$ & $0(0)$ & $0(0)$ & $0(0)$ & $0(0)$ & $0(0)$ & $0(0)$ & $0(0)$ & $1(3.3)$ & $1(.6)$ \\
\hline & $\mathbf{W}$ & $0(0)$ & $0(0)$ & $0(0)$ & $0(0)$ & $0(0)$ & $0(0)$ & $0(0)$ & $0(0)$ & $0(0)$ & $0(0)$ \\
\hline & $\mathbf{T}$ & $1(3.3)$ & $0(0)$ & $0(0)$ & $0(0)$ & $0(0)$ & $0(0)$ & $0(0)$ & $0(0)$ & $1(3.3)$ & $1(.6)$ \\
\hline \multirow[t]{3}{*}{ Group VI } & W/o & $0(0)$ & $0(0)$ & $0(0)$ & $0(0)$ & $1(3.3)$ & $0(0)$ & $0(0)$ & $0(0)$ & $1(3.3)$ & $1(.6)$ \\
\hline & W & $0(0)$ & $0(0)$ & $0(0)$ & $0(0)$ & $0(0)$ & $0(0)$ & $0(0)$ & $0(0)$ & $0(0)$ & $0(0)$ \\
\hline & $\mathbf{T}$ & $0(0)$ & $0(0)$ & $0(0)$ & $0(0)$ & $1(3.3)$ & $0(0)$ & $0(0)$ & $0(0)$ & $1(3.3)$ & $1(.6)$ \\
\hline \begin{tabular}{|l|} 
Total \\
(\% of all)
\end{tabular} & $19(10.6)$ & $8(4.4)$ & $3(1.7)$ & $6(3.3)$ & $7(3.9)$ & $\begin{array}{l}20 \\
(11.1)\end{array}$ & $2(1.1)$ & $1(.6)$ & $\begin{array}{l}66 \\
(36.7)\end{array}$ & & \\
\hline
\end{tabular}

* W/o - patients with limitations without complaints, in absolute numbers and (per cent)

** W-patients with limitations and complaints, in absolute numbers and (per cent)

***T - patients with limitations, in absolute numbers and (per cent) 
There were no gender differences detected among conservatively and operatively treated groups $\left(p=1.000, \chi^{2}=.000 ; d f=1\right)$, both girls and boys had 53.3 $\%$ limitation rate $(n=32 ; 95 \%$ CI 40.9-65.4).

Analyzing injured side in aspect of hand dominance, it became clear that dominant hand was injured more often (ratio $=1.14: 1$ ). Analyzing age structure, no statistically significant differences were found in all three age groups (7-9 years, $\mathrm{p}=.196 \chi^{2}=1.674 ; \mathrm{df}=1$; $10-12$ years $\mathrm{p}=.155 ; \chi^{2}=2.026 ; \mathrm{df}=1$; and $13-15$ years $\mathrm{p}=.897 ; \chi^{2}=.017 ; \mathrm{df}=1$ ) in both genders, comparing to other age groups of the same gender (see Table 3 ).

Table 3. Distribution of injuries and limitations of ROM by age and hand dominance, including range of limitations causing subjective complaints

\begin{tabular}{|c|c|c|c|c|c|c|c|c|c|}
\hline & Age, years & $\begin{array}{l}\text { Dominant } \\
\text { (D) }\end{array}$ & $\begin{array}{l}\text { Injured } \\
\text { (I) }\end{array}$ & D-I & Limitations & Complaints & & & \\
\hline & & Dx & Sin & Dx & Sin & & & $\mathrm{n}$ & Degrees \\
\hline \multirow[t]{3}{*}{ Group I } & $7-9$ & 8 & 2 & 5 & 5 & 7 & 7 & 0 & \\
\hline & $10-12$ & 10 & 0 & 7 & 3 & 6 & 8 & 1 & 20 \\
\hline & $13-15$ & 8 & 2 & 5 & 5 & 8 & 7 & 4 & $22 / 23 / 25 / 22$ \\
\hline \multirow[t]{3}{*}{ Group II } & $7-9$ & 9 & 1 & 6 & 4 & 7 & 8 & 1 & 25 \\
\hline & $10-12$ & 7 & 3 & 5 & 5 & 2 & 7 & 1 & 24 \\
\hline & $13-15$ & 8 & 2 & 5 & 5 & 5 & 8 & 3 & $22 / 22 / 25$ \\
\hline \multirow[t]{3}{*}{ Group III } & $7-9$ & 9 & 1 & 5 & 5 & 4 & 2 & 1 & 21 \\
\hline & $10-12$ & 7 & 3 & 6 & 4 & 5 & 5 & 2 & $24 / 25$ \\
\hline & $13-15$ & 9 & 1 & 5 & 5 & 6 & 3 & 1 & 22 \\
\hline \multirow[t]{3}{*}{ Group IV } & $7-9$ & 8 & 2 & 5 & 5 & 5 & 1 & 0 & \\
\hline & $10-12$ & 8 & 2 & 8 & 2 & 6 & 5 & 1 & 20 \\
\hline & $13-15$ & 10 & 0 & 4 & 6 & 4 & 3 & 2 & $23 / 20$ \\
\hline \multirow[t]{3}{*}{ Group V } & $7-9$ & 9 & 1 & N/A & N/A & N/A & 0 & N/A & N/A \\
\hline & $10-12$ & 9 & 1 & N/A & N/A & N/A & 0 & N/A & N/A \\
\hline & $13-15$ & 7 & 3 & N/A & N/A & N/A & 1 & N/A & N/A \\
\hline \multirow[t]{3}{*}{ Group VI } & 7-9 & 8 & 2 & N/A & N/A & N/A & 0 & N/A & N/A \\
\hline & $10-12$ & 8 & 2 & N/A & N/A & N/A & 0 & N/A & N/A \\
\hline & $13-15$ & 8 & 2 & N/A & N/A & N/A & 1 & N/A & N/A \\
\hline Total & & 150 & 30 & & & 65 & 66 & & \\
\hline
\end{tabular}

\section{DISCUSSION}

The main question of our study was „Does operative treatment of forearm midshaft fractures in children provide better results than conservative approach?" Stratified randomization of patients along with objective (ROM assessment) and subjective (PedsQL questionnaires) parameter analysis provided us reliable and reproducible data.

Overall results of our study pointed out that surgical treatment is a more effective method compared to conservative treatment. Modern intramedullary nailing techniques allow optimization of treatment parameters (intervention breadth, duration of admittance, treatment expenses, functional outcomes and quality of life, due to increased stability of bone fractures, reduced immobilization period and complications associated with prolonged plaster wearing - joint stiffness and reduction in ROM (33). Assessment of bone healing revealed normal healing process both in conservatively and operatively treated patients, avoiding complications as malunion and nonunion. 3 patients of group I and 4 patients of group II were expelled due to malalignment, requesting additional manipulation and intramedullary fixation due to unacceptable secondary dislocation. No malalignment was documented in both surgically treated groups III and IV that advocates for better bone stability in these children. Other causes of exclusion were poor compliance - refusal or defiance of recommended follow-up, one case of deep wound infection and two cases when respondents chose to remove the nails before the appointed follow-up term. Controversial opinions about acceptable displacement, rotation and angulation exist. It is considered that patients under 10 years of age can tolerate increased level of displacement (even complete), rotation (up to $45^{\circ}$ ) and angulation (up to $\left.15^{\circ}\right)(9,12,13,23)$. Children over 10 years of age are supposed to tolerate up to $10^{\circ}$ of angulation and $50 \%$ displacement; 
greater deviations and malrotation request operative intervention $(9,12,24)$.

Analyzing both conservatively and surgically treated groups we found that they differed from controls group, it suggests correct respondent selection. Limitations of ROM were significantly higher in both conservatively treated groups, regardless of age subgroups, suggesting that operative treatment using ESIN should not be limited as golden standard for treatment of adolescents with forearm midshaft fractures only, but implemented in younger age groups as well.

Most of the limitations were asymptomatic that depicts the high level of compensatory and adaptive capacities of a growing child. Some authors suggest that the functional ROM of the wrist utilized in most daily tasks is smaller than the actual ROM available for the wrist $(3,16)$. Assessment of ROM in aspect of subjective complaints revealed that no severe limitations were detected in this study, only mild or moderate limitations were identified and only the latter caused subjective complaints. This can be an explanation why children have seldom complaints and potential ROM limitation has not been included in argument list while choosing the proper treatment method.

Analysis of anatomical aspects of ROM limitations revealed that most of the limitations affected flexionextension movements in sagittal plane around frontal axis. Forearm shaft fractures usually impact rotation movements - pronation and supination (20), but we identified just some cases of this limitation type in our study. Some authors believe that $60 \%$ of patients after these fractures have $>20^{\circ}$ limitations of rotation (9). Still subjective results are good and limited ROM can be identified only performing goniometry (37). Functionally shoulder compensates loss of pronation by abduction and internal rotation, but loss of supination is compensated by adduction and external rotation (9).

The two respondents with mild limitations of ROM in control groups were asymptomatic and should be considered as incidental finding.

Limitations of ROM showed no significant differences between boys and girls neither from the aspect of incidence nor frequency of subjective complaints. According to this study we do not recommend to use gender as an argument choosing the treatment. Rather similar is the aspect of patient age. We could not establish statistically significant correlation, proving that limitations are found more often in younger or older children, but what we found is the difference of treatment efficiency in favor of surgical approach. We have used to consider that surgery is used more for older children, while younger children usually undergo conservative treatment, they have faster healing and thus - better functional outcome $[29,33,37]$. Our results with patient randomization showed that there are no differences among age groups treated by the same method. This means that the chosen method of treatment per se has the main influence on the incidence of ROM limitations.

Analyzing influence of the dominating hand, we found that it was injured more often (1.14:1). This is an interesting finding, because usually dominant hand is considered to be "stronger", as it is more used, has increased muscle mass and better tolerance to similar impact $(11,33)$.

Despite the wide use of goniometry in physical therapy for objective assessment or ROM, the reliability of using it under clinical settings is variable, and depends significantly on experience of tester and performance of the assessment (intratester errors), number or persons performing the same study (intratester errors), and tool used (intertool errors) $(15,17,27)$. In most cases assessing arm motion range by the same person and the same tool (like it was in our study), the reliability is high $(5,14)$. Publications also suggest that expensive electronic devices do not guarantee higher precision of measurement compared to simple plastic goniometer (used in our study), and taking single measurement is enough $(2,21)$. Still we performed so called "test-retest" assessment model with two consequent measurements, separated by short time interval which is supposed to be the most accurate performance of measurement.

Validity of goniometry means the goniometer and measurement procedures are accurate and we understand the meaning of the measurement results. Although insignificant errors in the construction of goniometers may exist, the instruments generally are accepted as valid clinical tools $(5,15,32)$.

The reliability and the validity of even simple measurements, however, may be decreased because of patient differences that we cannot control. Obesity and variations in bony structures can make accurate visual inspection and bony palpation very difficult $(2,14,17)$.

Many authors suggest that it is more difficult to measure reliably passive ROM than active ROM. Amis and Miller stated this problem as follows: "Passive movements are extremely difficult to reproduce, because the stretching of soft tissues at the limits of motion depends on the force applied to the limb, which must, therefore, be carefully controlled" (1). Bird indicated that measurement error in the wrist joint was higher in passive movements, compared to active (4). Wagner suggested that variability of passive flexibility was higher than that of active variability (36).

Some authors have questioned the necessity of surgical treatment, because in their opinion conservative treatment provides acceptable results without any surgical intervention, especially in younger children $(10,19,28,31,34)$. Others advocate for elastic stable intramedullary nailing, but set lower age limits of the method to 8-10 years $(6,7)$. Some enthusiasts of ESIN point out the lack of necessity in postoperative immobilization and consider early mobilization to be the main argument for surgery (29). Relatively 
low compliance of children and the ultimate level of activity, may endanger treatment results, besides the overall level of children activity is more than enough to mobilize arm after removal of plaster without special rehabilitation program. Therefore we do not recommend avoidance of postoperative immobilization.

Only few surgical alternatives are provided to ESIN for treatment of diaphyseal forearm fractures $-K$-wire osteosynthesis $(18,30)$, Steinmann pin implantation (25), along with use of semitubular plates (35) and ExFix (29), but none of them has proved to be superior in pediatric population due to debatable anatomic, functional or cosmetic considerations.

Another question that remains unanswered is whether surgical treatment could be superior upon conservative treatment followed by rehabilitation in aspect of functional outcome. In this study we compared only children without post-treatment rehabilitation course, in order to make groups comparable, still this issue can be a good clinical question for the further research.

\section{CONCLUSIONS}

The results of this study indicate superior effectiveness of elastic stable intramedullary nailing over conservative approach. Frequency of ROM limitations performing surgical stabilization is more than twice lower than that of conservatively treated children. Only moderate $\left(>20^{\circ}\right)$ limitations of ROM cause subjective complaints. Although compensatory capacities of a growing child are high and therefore most limitations of ROM are asymptomatic and do not reduce quality of life, it advocates surgical treatment to become the golden standard for midshaft forearm fracture treatment in pediatric population. The age and gender of a child does not influence frequency and severity of ROM limitations therefore should not be considered as the main arguments while choosing treatment method.

\section{Conflict of interest: None}

\section{REFERENCES}

1. Amis AA, Miller JH: The elbow. // Clin Rheum Dis, 1982; 8:571-93.

2. Armstrong AD, MacDermid JC, Chinchalkar S, et al. Reliability of range-of-motion measurement in the elbow. // J Shoulder Elbow Surg 1998; 7:57380 .

3. Berger RA. The anatomy and basic biomechanics of the wrist joint. // J Hand Ther 1996; 9:84-93.

4. Bird HA, Stowe J: The wrist. // Clin Rheum Dis, 1982; 8:559-69.

5. Boone DC, Azen SP, Lin CM et al. Reliability of goniometric measurements. // Phys Ther. 1978; 58:1355-60.

6. Bowman EN, Mehlman CT, Lindsell CJ, Tamai J. Nonoperative treatment of both-bone forearm shaft fractures in children: predictors of early radiographic failure. // J Pediatr Orthop. Jan-Feb $2011 ; 31(1): 23-32$
7. Charles TM, Enric JW. Injuries to the shafts of the radius and ulna. // In: Rockwood $\delta$ Wilkins' Fractures in Children. Ed. by Beaty JH, Kasser JR 6th ed. -Lippincott Williams \& Wilkins, 2006: 40038.

8. Cheng JC, Ng BK, Ying SY, et al. A 10-year study of the changes in the pattern and treatment of 6,493 fractures. // J Pediatr Orthop. 1999; 19(3):344-50.

9. Daruwalla JS. A study of radioulnar movements following fractures of the forearm in children. // Clin Orthop Relat Res. 1979; 139:1 14-120.

10. Dhar D, Varghese TP. Audit of Inpatient Management and Outcome of Limb Fractures in Children. // Oman Medical Journal, 2011; 26 (2): 132-4.

11. Freih $\mathrm{OAH}$. Hand dominance and gender in forearm fractures in children. // Strategies Trauma Limb Reconstr, 2008; 3(3): 101-3.

12. Fuller DJ, McCullough CJ. Malunited fractures of the forearm in children. // J Bone Joint Surgery Br. 1982; 64:364-367.

13. Ghandi RK, Wilson P, Mason Brown JJ, MacLeod W. Spontaneous correction of deformity following fractures of the forearm in children. // Br J Surg. 1962; 150:5-10.

14. Goodwin J, Clark C, Deakes J et al. Clinical methods of goniometry: a comparative study. // Disabil Rehabil, 1992; 14: 10-5.

15. Hellebrandt FA, Duvall EN, Moore ML. The measurement of joint motion: Part III - Reliability of goniometry. // Phys Ther Rev, 1949; 29: 302-7.

16. Kapandji A. The radio-ulnar unit. Its functional importance in fractures of both bones of the forearm. // Chir Main 1998; 17:348-61.

17. Low JL: The reliability of joint measurement. // Phys Ther, 1976; 62:227-9.

18. Luhmann SJ, Gordon JE, Schoenecker PL. Intramedullary fixation of unstable both-bone forearm fractures in children. // J Pediatr Orthop 1998; 18:451-6.

19. Madhuri V, Dutt V, Gahukamble AD, Tharyan P. Conservative interventions for treating diaphyseal fractures of the forearm bones in children. // Cochrane Database Syst Rev 2013; 4:CD008775.

20. Matthews LS, Kaufer H, Garver DF, et al. The effect on supination-pronation of angular malalignment of fractures of both bones of the forearm. // J Bone Joint Surg Amer 1982; 64:14-7.

21. Petherick M, Rheault W, Kimble S et al. Concurrent validity and inter-tester reliability of universal and fluid based goniometers for active elbow range of motion. // Phys Ther, 1988 68: 966-9.

22. Price CT, Flynn JM. Management of fractures. // In: Lovell and Winter's Pediatric Orthopaedics, 6th, Morrissy RT, Weinstein SL. (Eds), Lippincott Williams \& Wilkins, Philadelphia; 2006; 1429-1526.

23. Price CT, Mencio GA. Injuries to the shafts of the radius and ulna. // In: Beaty JH, Kasser JR, eds. Rockwood and Wilkins' Fractures in Children. 5th ed. Philadelphia, Pa: Lippincott Williams \& Wilkins; 2001:443-482. 
24. Price CT, Scott DS, Kurzner ME, Flynn JC. Malunited forearm fractures in children. // J Pediatr Orthop. 1990; 10:705-12.

25. Pugh DMW, Galpin RD, Carey TP. Intramedullary Steinmann pin fixation of forearm fractures in children: long-term results. // Clin Orthop 2000; 376:39-48.

26. Rodríguez-Merchán EC. Pediatric fractures of the forearm. // Clin Orthop Relat Res. 2005 Mar; (432): 65-72.

27. Rothstein J, Miller P, Roettger R. Goniometric reliability in a clinical setting. Elbow and knee measurements. // Phys Ther. 1983; 63:1611-5.

28. Samora JB, Klingele KE, Beebe AC, et al. Is There Still a Place for Cast Wedging in Pediatric Forearm Fractures? // J Pediatr Orthop. Sep 152013.

29. Schmittenbecher PP. State-of-the-art treatment of forearm shaft fractures. // Injury 2005; 36 Suppl.1:A 25-34.

30. Shoemaker SD, Comstock CP, Mubarak SJ, et al. Intramedullary Kirschner wire fixation of open or unstable forearm fractures in children. // J Pediatr Orthop 1999; 19:329-37.

31. Singh S, Bhatia M, Housden P. Cast and padding indices used for clinical decision making in forearm fractures in children. // Acta Orthop. Jun 2008; 79(3):386-9.

32. Solgaard S, Carisen A, Kramhoft $M$, et al: Reproducibility of goniometry of the wrist. // Scand J Rehabil Med, 1986; 18:5-7.
33. Upenieks J, Sloka S, Petersons A, Villerusa A. A 5 -year overview of forearm fracture etiology and treatment options in 7-15 year old children. // Acta Chir Latviensis, 2012; 12(1):36-40.

34. Valerio G, Gallè F, Mancusi C, et al. Pattern of fractures across pediatric age groups: analysis of individual and lifestyle factors. // BMC Public Health, 2010; 10: 4-9.

35. Van der Reis WL, Otsuka NY, Moroz P, et al. Intramedullary nailing versus plate fixation for unstable forearm fractures in children. // J Pediatr Orthop. 1998; 18:9-13.

36. Wagner C: Determination of the rotary flexibility of the elbow joint. // Eur J Appl Physiol , 1977; 37:4759.

37. Zionts LE, Zalavras CG, Gerhardt MB. Closed treatment of displaced diaphyseal both-bone forearm fractures in older children and adolescents. // J Pediatr Orthop 2005; 25:507-12.

\section{Address:}

Janis Upenieks

Department of Pediatric Surgery

University Children's Hospital

Vienibas gatve 45

LV-1004 Riga, Latvia

E-mail: dr.upenieks@gmail.com 